\title{
Praktik Pembelajaran di Madrasah Perspektif Pragmatisme (Studi Terhadap Pemikiran Ibn Khaldun dan Jhon Dewey)
}

\author{
${ }^{1 *}$ Rz. Ricky Satria Wiranata, ${ }^{2}$ Arham Junaidi Firman, ${ }^{3}$ Tri Mulyanto, ${ }^{4}$ Agung Ilham \\ Prastowo \\ 1Prodi Manajemen Dakwah STAI Terpadu Yogyakarta \\ ${ }^{234}$ Doktoral PAI FITK UIN Sunan Kalijaga \\ 1* $\underline{\text { rickysatriawiranata@gmail.com, 2arhamjf@yahoo.com }{ }^{3} \text { masmule3@gmail.com, }}$ \\ 4agungelham684@gmail.com
}

\begin{abstract}
Abstrak: Artikel ini berusaha mencari format praktik pembelajaran di Madrasah dalam perspektif pragmatisme. Artikel ini menarik karena mencoba membenturkan dua filosof besar dikalangan Islam dan Barat yaitu Ibn Khaldun dan Jhon Dewey kemudian di komparasi dan di reposisi menjadi sebuah temuan konsepsi praktis pembelajaran di Madrasah. Artikel ini merupakan studi Pustaka (library research) yaitu prosedur mengumpulkan data dari berbagai karya tulis seperti buku, artikel, catatan ilmiah kemudian di telaah secara dialogis menjadi sebuah simpulan. Pendekatan yang digunakan dalam artikel ini adalah filosofis. Hasil penelitian menyatakan bahwa ciri khas dari pendidikan pragmatis adalah praktek langsung (Learning by Doing). Madrasah tidak hanya berfungsi sebagai tempat mengasah kecerdasan kognitif tetapi juga sebuah laboratorium pengalaman tempat ide dan gagasan diuji coba. Tujuan Pendidikan pragmatis di madrasah adalah pengembangan pemikiran, kesadaran sosial dan peningkatan kerohanian siswa. Praktik pembelajaran pragmatis hendaknya dimulai dari pengalaman hidup yang bersifat umum menuju yang lebih kompleks. Kurikulum Pendidikan pragmatis di madrasah hendaknya menyesuaikan dengan kemampuan inteletual siswa. Pembelajaran pragmatis hendaknya membuat siswa mampu memetik intisari pelajaran, keterangan dan penjelasan yang komprehensip multi perspektif.
\end{abstract}

Kata kunci : Pembelajaran, Madrasah, Pragmatisme

\begin{abstract}
This article tries to find the format of learning practices in Madrasas in the perspective of pragmatism. This article is interesting because it tries to clash two major philosophers among Islam and the West, namely Ibn Khaldun and Jhon Dewey, then compared and repositioned into a finding of a practical conception of learning in Madrasas. This article is a literature study (library research), which is the procedure of collecting data from various papers such as books, articles, scientific notes, and then studying it dialogically into a conclusion. The approach used in this article is philosophical. The results of the study stated that the characteristic of pragmatic education is direct practice (Learning by Doing). Madrasah not only function as a place to sharpen cognitive intelligence but also a laboratory of experiences where ideas and ideas are tested. The purpose of pragmatic education in madrasas is the development of thinking, social awareness, and the improvement of students' spirituality. Pragmatic learning practices should start from general life experiences to more complex ones. The pragmatic education curriculum in madrasas should adapt to student's intellectual abilities. Pragmatic learning should make students able to reap the essence of lessons, explanations, and explanations that are multi-perspective comprehensive.
\end{abstract}

Keywords : Learning, Madrasah, Pragmatism

Al-Manar : Jurnal Komunikasi dan Pendidikan Islam - Volume 10, Nomor 1, Juni 2021 


\section{PENDAHULUAN}

Pembelajaran merupakan sesuatu yang urgen dalam proses penentuan kualitas out put pendidikan, untuk menjadikan peserta didik dewasa, mandiri, kreatif, inovatif, kritis dan tanggap dalam bertindak. Dengan demikian atmosfir pembelajaran peserta didik harus dapat merangsang berfikir secara mandiri dan kritis (independent critical thinking) dalam rangka menemukan jati dirinya. Dalam konteks ini yang terpenting bukanlah transfer of knowledge yang bersifat taken for granted oleh peserta didik, namun bagaimana mengajarkan peserta didik untuk aktif (bertindak \& berpikir), dewasa, kreatif dan inovatif dalam menentukan tindakan yang akan diambil sessuai dengan keputusan yang diharapkan. Salah satu upaya untuk mewujudkan harapan itu adalah dengan cara pendekatan metode praktik pragmatisme dalam pembelajaran.

Pragmatisme dapat diartikan sebagai pendekatan terhadap masalah hidup apa adanya dan secara praktis, bukan teoritis atau ideal, hasilnya dapat dimanfaatkan, langsung berhubungan dengan tindakan, bukan spekulasi atau abstraksi. Dengan hadirnya praktik pembelajaran di madrasah dengan pendekatan perspektif pragmatisme tersebut peneliti memandang akan melahirkan kesempurnaan dalam pembelajaran serta dapat menghasilkan out put yang berkualitas tinggi dalam pendidikan jika dikaitkan dengan dua tokoh pragmatisme perspektif Islam dan Barat.

Berangkat dari latar belakang di atas peneliti tertarik ingin melihat secara universal gagasan dari dua tokoh pragmatisme tersebut. Teori yang digagas oleh tokoh Islam yang diwakili oleh Ibnu Khaldun dan Barat diwakili oleh John Dewey sangat menarik untuk dibahas secara tuntas, sebagai tambahan wawasan dalam pengembangan pembealajaran pendidikan Islam. Oleh karena itu peneliti akan mendeskripsikan teori pendidikan yang digagas oleh dua tokoh tersebut dalam praktik pembelajaran di madrasah perspektif pragmatisme.

\section{METODE PENELITIAN}

Artikel ini adalah penelitian kualitatif. Pendekatan dalam artikel ini adalah analisi kritis filosofis terhadap pemikiran pragmatisme yang berkembang di dunia Islam dan Barat. Sumber data dalam penelitian ini adalah studi Pustaka (library research) yaitu prosedur mengumpulkan data dari berbagai kepustakaan ${ }^{1}$ seperti buku, artikel, catatan ilmiah dan lain sebagianya, kemudian di telaah secara kritis dan dialogis menjadi sebuah simpulan.

\footnotetext{
${ }^{1}$ Joko Subagyo, Metode Penelitian dan Praktek, (Jakarta: Rhineka Cipta, 1991), 109
} 


\section{PEMBAHASAN}

\section{A. Mengenal Pragmatisme Ibn Khaldun}

Ibnu Khaldun merupakan satu-satunya tokoh Islam yang mempelopori hadirnya pragmatisme. Jika ditinjau dari sudut pandang dari pendidikan, Ibnu Khaldun lebih banyak bersifat pragmatis dan lebih berorientasi pada aplikatif-praktis. Konsep pendidikan Ibnu Khaldun menghubungkan antara konsep dan realita, merupakan hasil dari berbagai pengalaman yang dilaluinya sebagai seorang ahli filsafat sejarah dan sosiologi. ${ }^{2}$

Ibnu Khaldun mengklasifikasikan ilmu pengetahuan berdasarkan tujuan fungsionalnya, bukan berdasarkan nilai substansialnya semata. Ibnu Khaldun membagi ilmu pengetahuan menjadi dua bagian yang perlu dimasukan kedalam kurikulum pendidkan, yaitu:

1. Ilmu yang mempunyai nilai instrinsik, contoh ilmu syar' iyyat (keagamaan): Tafsir, Hadis, Fikih, Kalam, Ontologi dan Teologi dari cabang fisafat.

2. Ilmu yang mempunyai nilai ekstrinsik-instrumental bagi ilmu-ilmu sejenis pertama, contoh bahasa Arab, ilmu Hitung dan sejenisnya bagi ilmu syar'iy, Logika bagi Filsafat dan bahkan menurut ulama' Muta' akhirin dimasukan juga ilmu Kalam dan Usul Fikih.

Beranjak dari orientasi kepraktisan, Ibnu Khaldun membolehkan pendalaman ilmu-ilmu yang berkaitan dengan ilmu yang mempunyai nilai instrinsik. Ia membolehkan membahas lebih dalam terkait masalah ilmu yang mempunyai nilai instrinsik untuk dibahas dan didiskusikan secara analitik-rasional. Sebab ilmu ini dapat meningkatkan intelektualitasakademik seseorang. Sedangkan ilmu yang mempunyai nilai ekstrinsikinstrumental Ibnu Khaldun tidak membolehkan diskursus rasional tentang ilmu ini, melainkan jika diletakan dalam kerangka kegunaan bagi jenis ilmu yang bernilai instrinsik. Atas dasar pertimbangan praktis itu, Ibnu Khaldun mengecam kalangan ahli nahwu, ahli logika dan ahli fikih masanya, karena mereka telah memperluas lingkup kajian dan memperbanyak topik bahasan dan argumentasi bagi disiplin ilmu mereka, hingga keluar dari maksud semula sebagai ilmu bantu dan berubah menjadi ilmu instrinsik. Menurut Ibnu Khaldun, hal ini menggiring kearah negatif bagi murid secara umum. Seharusnya murid lebih banyak perhatiannya kearah ilmu instrinsik malah

${ }^{2}$ Hamam Burhanuddin, Dekontruksi Pemikiran Ibnu Khaldun Tentang Pendidikan, Edukasi, Volume 03, Nomor 01, Juni, 2015, 704 
disibukan oleh ilmu instrumental. Seharusnya guru memberikan peringatan kembali terkait masalah tujuan pendidikan yang akan dicapai oleh murid. Klasifikasi pragmatis keilmuan yang harus dipelajari oleh murid tersebut bukanlah satu-satunya pola klasifikasi ilmu Ibnu Khaldun. Ia memperkenalkan pola klasifikasi lain yang didasarkan pada sumber ilmu. Ibnu Khaldun mengutarakan ada dua sumber ilmu yang paling utama, yaitu:

1. Bersifat alamiah, yaitu ilmu yang diperoleh manusia melalui olah-pikir rasio.

2. Bersifat sosiologis, yaitu ilmu yang diperoleh manusia melalui hasil transmisi dari satu generasi ke generasi berikutnya melalui cara indroktrinasi dan pengajaran. ${ }^{3}$

Berdasarkan sumber ilmu di atas, Ibnu Khladun membagi kurikulum pendidikan menjadi dua tingkatan: 4

1. Tingkat dasar, yaitu mendalam Al-Qur'an sebagai dasar agama dan sumber ilmu. Materi Al-Qur'an akan menjadikan siswa mempunyai dasar akidah yang kuat dan berkarakter.

2. Tingkat atas, tingkatan ini mencakup dua hal: (1) Ilmu yang berkitan dengan zatnya sendiri seperti Ilmu Syariah atau Ilmu agama, (2) Ilmu yang ditujukan ilmu lain dan bukan berkaitan dzat Allah atau ilmu umum.

Dalam aspek pendidik, Ibnu Khaldun mengemukakan bahwa seorang pendidik akan berhasil dalam tugasnya apabila memiliki sifat-sifat yang mendukung profesionalismenya. Adapun sifat-sifat tersebut adalah pendidik hendaknya lemah lembut, senatiasa menjauhi sifat kasar, serta menjauhi hukuman yang merusak fisik dan psikis peserta didik, terutama terhadap anak-anak yang masih kecil, pendidik hendaknya menjadikan dirinya sebagai Uswah al-Hasanah (suri teladan) bagi peserta didik. ${ }^{5}$ Keteladan menjadi hal inti dalam pendidikan, karena bagi Ibnu Khaldun anak akan mudah meniru apa yang dilakukan oleh guru daripada hanya sekedar kata-kata nasehat atau perintah. ${ }^{6}$

\footnotetext{
${ }^{3}$ Muhammad Jawwad Ridla, Tiga Aliran Utama Teori Pendidikan Islam, perspektif SosiologisFilosofis, (Yogyakarta: Tiara Wacana), 104-106

${ }^{4}$ Siti Rohmah, Relevansi Konsep Pendidikan Islam Ibnu Khaldun Dengan Pendidikan Modern, Forum Tarbiyah Vol. 10, No. 2, Desember 2012, 277

${ }^{5} \mathrm{Abd}$. Al-Rahman Ibn Khaldun, Muqaddimah Ibn Khaldun, Tahqiq Ali Abd al-Wahid Wafi, (Cairo: Dar al-Nandhah, 1982), 1253.

${ }^{6}$ Muh. Barid Nizaruddin Wajdi, Pendidikan Ideal Menurut Ibnu Khaldun dalam Muqaddimah, Jurnal Lentera: Kajian Keagamaan, Keilmuan dan Teknologi Volume 1, Nomor 2, September 2015,. 276
} 
Dalam aspek Metode Pengajaran, seorang pendidik harus mampu mengajar dengan baik, ia mengungkapkan ada tiga langkah metode mengajar. ${ }^{7}$

1. Hendaknya kepada peserta didik di ajarkan pengetahuan yang bersifat umum dan sederhana, khusus berkenaan dengan pokok bahasan yang tengah dipelajari. Pengetahuan ini hendaknya disesuaikan dengan tarap kemampuan intelektual peserta didik, sehingga tidak berada di luar kemampuannya untuk memahami. Hendaknya peserta didik belajar pada tingkat pertama atau paling sederhana.

2. Seorang pendidik kembali menyajikan pengetahuan tersebut kepada peserta didik dalam tarap yang lebih tinggi dengan memetik intisari pelajaran, keterangan dan penjelasan yang lebih spesifik. Dengan demikian pendidik dapat mengantarkan peserta didik kepada tarap pemahaman yang lebih tinggi.

3. Seorang pendidik mengajarkan pokok bahasan tersebut secara lebih terinci dalam konteks yang menyeluruh, sambil memperdalam aspek-aspek dan menajamkan pembahasannya. Tidak ada lagi yang sulit dan yang tidak diterangkan ataupun dibahasnya.

Dalam aspek tujuan pendidikan menurut Ibn Kholdun, maka Pendidikan hendaknya membentuk pribadi peserta didik agar lebih dewasa yang mempunyai berbudi tinggi, luhur, berkepribadian mulia melalui nilainilai pendidikan dalam Al-Qur'an. Membentuk akhlak mulia pada peserta didik merupakan tujuan pokok dalam konsep pendidikan Ibnu Khaldun karena akhlak yang akan menjadi tolok ukur kemulian hidup manusia di dunia dan akherat. Ketika menganjak remaja maka tujuan pendidikan harus ditambah dengan keahlian atau ketrampilan untuk hidup di dunia. Pada masa remaja dan dewasa seseorang diberi kebebasan dalam berfikir dan mengembangkan ilmu pengetahuan. Keterbukaan akan terhadap ilmu pengetahuan akan membawa kepada kesejahteraan hidup di dunia dan sebagai sarana untuk hidup berbudaya dan bermartabat. ${ }^{8}$ Secara terperinci tujuan pendidikan Ibnu Khaldun dijelaskan sebagai berikut: ${ }^{9}$

${ }^{7}$ Muh. Barid Nizaruddin Wajdi, Pendidikan Ideal Menurut Ibnu Khaldun....... 394.

8 Ahmad Falah, Konsep Pendidikan Anak Menurut Ibnu Khaldun (Studi Atas Kitab Muqaddimah), Thufula, Vol. 2, No. Januari-Juni 2014, 99

${ }_{9}^{9}$ Ahmad Falah, Konsep Pendidikan Anak Menurut Ibnu Khaldun 1018 
1. Tujuan Peningkatan Pemikiran

Ibn Khaldun memandang bahwa salah satu tujuan pendidikan adalah memberikan kesempatan kepada akal untuk lebih giat dan melakukan aktivitas. Hal ini dapat dilakukan melalui proses menuntut ilmu dan keterampilan. Dengan menuntut ilmu dan keterampilan, seorang akan dapat meningkatkan kegiatan potensi akalnya. Di samping itu, melalui potensinya, akal akan mendorong manusia untuk memperoleh dan melestarikan pengetahuan. Melalui proses belajar, manusia senantiasa mencoba meneliti pengetahuan-pengetahuan atau informasi-informasi yang diperoleh oleh pendahulunya. Manusia mengumpulkan fakta-fakta dan menginventarisasikan keterampilan-ketermapilan yang dikuasainya untuk memperoleh lebih banyak warisan pengetahuan yang semakin meningkat sepanjang masa sebagai hasil dari aktivitas akal manusia.

2. Tujuan Peningkatan Kemasyarakatan

Dari segi peningkatan kemasyarakatan, Ibn Khaldun berpendapat bahwa Ilmu dan pengajaran adalah lumrah bagi peradaban manusia. ${ }^{5}$ Ilmu dan pengajaran sangat diperlukan untuk meningkatkan taraf hidup masyarakat manusia kearah yang lebih baik. Semakin dinamis budaya suatu masyarakat, maka akan semakin bermutu dan dinamis pula keterampilan di masyarakat tersebut.

3. Tujuan Pendidikan dari Segi Kerohanian

Tujuan pendidikan dari segi kerohanian adalah dengan meningkatkan kerohanian manusia dengan menjalankan praktek ibadat, zikir, khalwat (menyendiri) dan mengasingkan diri dari khalayak ramai sedapat mungkin untuk tujuan ibadah sebagaimana yang dilakukan oleh pra sufi.

\section{B. Mengenal Pragmatisme Jhon Dewey}

Pragmatisme Pendidikan yang dipelopori oleh para filsuf yaitu John Dewey, William James dan Charls S. Pierce. Pragmatisme John Dewey didasarkan pada perubahan, proses, relatifitas, dan rekonstruksi pengalaman. Pragmatisme pendidikan Dewey cukup dipengaruhi oleh teori evolusi Charles Darwin bahwa semua makhluk hidup baik secara biologis maupun sosiologis memiliki naluri untuk bertahan hidup dan untuk berkembang. Sedangkan William James merumuskan pragmatisme sebagai bentuk penolakan dari dari prinsip, kategori dan keniscayaan awal yang beralih pada hasil, konsekuensi dan fakta baru. 
Menurut Dewey, pendidikan adalah upaya menolong manusia agar dapat berefleksi terhadap masalah yang timbul dalam masyarakat dan upaya memperlengkapi mereka agar menghasilkan perubahan yang nyata dalam kehidupan mereka. Jika dalam proses pendidikan tidak ada pengaruh yang positif terhadap ajaran dan masyarakar, maka janganlah disebut pendidikan,karena pendidikan harus memberikan pengaruh perubahan dan pertumbuhan. ${ }^{10}$

Rumusan Dewey tentang pendidikan adalah pembentukan kembali atau pengorganisasian ulang pengalaman yang menambah maknanya dan yang menambah kemampuan si pelajar dalam memberi arah terhadap pengalamanyang selajutnya. Proses pendidikan juga bersifat kontinu, merupakan reorganisasi, rekonstruksi, dan pengubahan pengalaman hidup. Dan untuk mencapai maksud tersebut, guru memiliki peranan penting untuk membimbing pelajar memperluas pengetahuan dan kemampuan berpikirnya dalam menjelajah hubungan baru yang dibangunnya di atas pengetahuan yang dimiiiki sebelumnya. ${ }^{11}$

Menurut Dewey, tujuan bukanlah berada di luar kehidupan, tetapi berada dalam kehidupan itu sendiri. Untuk itu, pembentukan pendidikan harus didasarkan pada lingkungan masyarakar di mana anak didik hidup dan tempat di mana pendidikan berlangsung. Tujuan yang ditetapkan haruslah khusus, tidak berlaku secara universal, dan temporer, karena tidak ada kebenaran dan nilai yang mutlak dan berlaku secara universal. Tujuan pendidikan adalah sebagai instrumen untuk bertindak, yang hasilnya akan menjadi instrument untuk pencapaian rujuan berikutnya dan dijadikan sebagai alat untuk bertumbuh. 12

Dari segi pragmatisme seorang pelajar merupakan subyek yang mempunyai pengalaman, sehingga menjadikannya mampu mengoptimalkan akalnya untuk mengatasi masalah-masalah. Dengan menggunakan akal atau intelekutualnya menjadikan seseorang berinteraksi dan beradaptasi sesuai dengan lingkungannya. Gagasan-gagasannya akan berkembang untuk mencapai keberhasilan dalam hidup. beranggapan bahwa anak didik adalah mahluk yang mempunyai kelebihan dibandingkan mahluk-mahluk lain, yaitu akal (pikiran) dan kecerdasan. Akal (pikiran) dan kecerdasan adalah

\footnotetext{
10 John Dewey, Democracy and Education, (Nerv York: Macmillan, 1964), 327

11 John Dewey, Democracy and Education ...., 328.

12 lryoh Sadulloh, Pengantar Filsat'at Pendidihan, (Bandung: Alfa Bera, 2007),128.
} 
bekal untuk menghadapi dan memecahkan problema-problema. ${ }^{13}$ Jhon Dewey sangat menekankan pada kebebasan peserta didik dalam mencari pengalaman, mereka adalah makhluk yang selalu berkembang maka pendidikan harus mampu membuat mereka berfikir kritis, sistematis dan peka terhadap lingkungan sekitar. ${ }^{14}$

Konsep guru dalam pragmatisme mempunya fungsi yang sangat penting yaitu menanamkan unsur esensial pengetahuan pada diri siswa (subyek didik). Guru dapat dilihat sebagai pembimbing siswa untuk menanamkan pengalaman karena dunia akan selalu mengalami perubahan setiap hatinya, sehingga siswa mampu mengambil pengalaman dari setiap aktivitasnya. Guru sebagai orang yang lebih berpemagalaman harus mampu mengarahkan dan membimbing semua kegiatan siswa berdasarkan pengalaman yang lebih luas. Guru dalam perspektif pendidikan aliran pragmatisme bukanlah guru yang terpaku pada diktat tetapi guru yang dituntut untuk kreatif. Guru harus belajar mempertahankan agar anak didik senang belajar dengan melihat dunia dari sudut pandang anak-anak serta sudut pandang orang dewasa. ${ }^{15}$

Konsep kurikulum menurut para tokoh pragmatisme terutama John Dewey yaitu harus berlandaskan pada unit-unit alamiah (wajar) sehingga tidak memunculkan problem atau menekan siswa. Kurikulum setiap tingkatan kelas bisa saja berbeda, tetapi gagasan utamanya yaitu bahwa materi sekolah seperti sejarah, matematika, sains dapat dikaitkan dengan teknik pemecahan masalah. Sehingga siswa akan belajar tentang pemecahan masalah yang mereka hadapi dalam reali1tas kehidupan. ${ }^{16}$

Dari segi metodologi, aliran pragmatisme mengorientasikan pada kebebasan kepada para siswa dalam mencari pengalaman belajarnya yang akan membentuk karakter mereka. Sehingga sekolah tidak hanya berfungsi sebagai tempat mengasah kecerdasan kognitif tetapi juga sebuah laboratorium pengalaman yang mana ide-ide atau gagasan dapat diuji coba. Dalam pandangan pragmatisme bahwa karyawisata lebih dapat memberi

${ }^{13}$ Iman, Muis Saad, Pendidikan Partisipatif: Menimbang Konsep Fitrah dan Progresivisme John Dewey, Yogyakarta, Safiria Insani Press, 2004. 58

${ }^{14}$ Musyarapah, The Role of Progressive Philosophy in the Curriculum Based on John Dewey's Theory, Al-hayat, Volume 01, Nomor 01, November 2017, 34

15 George R. Knight, Filsafat Pendidikan, terj Mahmud Arif, (Yogyakarta: Gama Media, 2007), 112-123.

${ }^{16}$ George R. Knight, Filsafat Pendidikan.....,120. 
pengalaman dari pada belajar membaca karena siswa lebih bebas mengekspresikan dirinya melalui interaksi dengan lingkungan. ${ }^{17}$

Dewey menegaskan bahwa belajar harus dimulai dengan pengalaman hidup (learning by doing) secara langsung menuju pada metode belajar atas pengalaman orang lain. Metode ini akan lebih berpengaruh pada pribadi siswa karena berdasarkan pengalaman- pengalaman dalam kehidupan sehari-hari. Sehingga proses pendidikan bukan sekedar menghafal materi pelajaran, melainkan menekankan lebih pada belajar untuk beradaptasi terhadap perubahan lingkungan. ${ }^{18}$

Konsep learning by doing merupakan aplikasi dari pemikiran pragmatisme pendidikan yang digagas oleh John Dewey. Dalam menghadapi industrialisasi Eropa dan Amerika, Dewey berpendirian bahwa sistem pendidikan sekolah harus diubah. Menurut Dewey, ilmu pengetahuan tidak hanya diperoleh dari buku-buku melainkan dapat diberikan kepada siswa melalui praktek dan tugas-tugas yang berguna. Belajar harus lebih banyak difokuskan melalui tindakan daripada melalui buku.

Dewey percaya terhadap adanya pembagian yang tepat antara teori dan praktek. Hal ini membuat Dewey demikian lekat dengan atribut learning by doing. Namun, bukan berarti Dewey menyeru anti intelektual, namun untuk menjelaskan bahwa manusia harus aktif, penuh minat dan minitikkan eksplorasi pengetahuan. ${ }^{19}$ John Dewey merinci metode pengajaran yang baik dan sesuai dengan usia perkembangan siswa, yaitu metode pengajaran progresif, yakni Learning by Doing Method, metode pemecahan masalah (problem solving), Metode pengajaran disiplin. ${ }^{20}$

\section{Implementasi Pragmatisme Di Madrasah}

Konsep Ibnu Khaldun dan Jhon Dewey mempunyai kesamaan dalam hal konsep belajar, bahwa belajar merupakan hasil dari pengalaman langsung dari peserta didik dan sesuai dengan tingkat perkembangan manusia. Peserta didik diberi kesempatan untuk melibatkan diri secara aktif

17 George R. Knight, Filsafat Pendidikan...., 121

18 George R. Knight, Filsafat Pendidikan....., 123.

19 Setiawan, A., Pengembangan Sebuah Ruang Kelas Belajar Serta Aplikasi Learning By Doing di Sekolah High Schope Indonesia, Proceedings: 1st International Symposium on Conducive Learning Environment for Smart School (Cles), 2011, 177.

20 T. Saiful Akbar , Manusia Dan Pendidikan Menurut Pemikiran Ibn Khaldun Dan John Dewey, Jurnal Ilmiah Didaktika Vol. 15, No. 2, Februari 2015,238 
dalam setiap proses pembelajaran dan dalam bimbingan seorang guru. ${ }^{21}$ Konsep pragmatisme yang telah dipaparkan pada poin sebelumnya memiliki implikasi dalam penyelenggaraan pendidikan agama Islam di madrasah, mulai dari materi yang harus diajarkan secara gradual hingga penggunaan metode proyek dalam pembelajaran. ${ }^{22}$

Ciri khas dari pendidikan pragmatis diantaranya adalah praktek langsung di lapangan sehingga siswa dapat memperoleh pengetahuan berdasarkan pengalaman empirisnya masing-masing. Sebagai contoh adalah guru mengajak siswa belajar mengenali anatomi hewan kurban, maka langkah pragmatisasinya adalah siswa diajak langsung ke tempat pemotongan hewan kurban kemudian melihat dan memegang langsung berbagai macam unsur-unsur yang berada dalam tubuh heban kurban tersebut. Sehingga siswa dapat mengetahui secara kongkrit apa dan bagaimana bentuk jantung, hati, empedu, tulang dan lain sebagainya.

Dalam contoh lain, konsep pragmatisme Ibnu Khaldun dan Jhon Dewey dalam pendidikan dapat dilihat dari pembelajaran Fiqh pada materi Wudhu', Shalat, Manasik Haji dan ibadah amaliyah lainnya. Dalam tulisan ini, penulis memfokuskan implementasi pragmatisme Ibnu Khaldun dan Jhon Dewey pada materi Shalat di Madrasah.

Implementasi materi shalat pada tingkatan dasar atau di Madrasah Ibtida'iyah yaitu dengan cara menirukan gurunya. Pada umumnya anak kelas 1-4 sebatas mengikuti kegiatan shalat berjamaah di masjid sekolah tanpa harus belajar dasar atau dalilnya. Sehingga anak dapat melihat dan mencontoh shalat yang baik dari gurunya. Selain itu, anak juga akan terbiasa melakukan shalat sejak dini. Dari sini anak akan mengambil pengalaman yang baik terkait motivasi melakukan shalat sehingga akan berpengaruh pada karakter.

Selanjutnya pada tingkatan kelas 5-6 anak tidak hanya menirukan apa yang dilakukan oleh gurunya, tetapi sudah harus mengetahui bacaan, tata cara shalat yang baik dan sesuai dengan tuntunan fiqh. Sehingga siswa mampu mengevaluasi apakah selama ini sudah melaksanakan shalat dengan baik atau belum dan mampu memperbaikinya. Sedangkan pada tingkat Madrasah Tsnawiyah anak dituntut untuk mengetahui dasar atau dalilnya

${ }^{21}$ Ilun Muallifah, Progrevisme Jhon Dewew dan pendidikan partisipatif dalam pendidikan Islam, Jurnal Pendidikan Agama Islam, volume 1, No 1, 2013, 115

22 Wasitohadi, "Pragmatisme, Humanisme dan Implikasinya Bagi Dunia Pendidikan di Indonesia", dalam Satya Widya, Vol. 28, No. 2, 2012, 175-189 
baik dari Al-Qur'an maupun As-sunah. Sehingga anak paham betul bahwa sholat tidak sekedar mengikuti orang lain tetapi menyadari bahwa shalat merupakan bentuk penghambaan pada Allah.

Pada tingkatan Madrasah Aliyah anak harus mampu mengidentifikasi dalil- dalil shalat yang berkaitan dengan shalat wajib atau sunnah melalui kajian usul fiqh. Di tingkatan ini siswa lebih kuat lagi pemahaman tentang esensi shalat. Selain itu siswa juga mempelajari perbandingan mazhab, khususnya mazhab fiqh. Dengan memahami perbedaan mazhab dalam shalat yang bersifat furu'iyyah (cabang) dapat menjadikan anak berfikiran luas dan menerima perbedaan tentang pelaksanaan shalat. Mereka mampu memahami kenapa orang-orang yang bermazhab Syafi'i cenderung berbeda dengan mazhab Hambali. Dengan demikian siswa mampu mengambil pengalaman pada tiap tingkatan pendidikan yang berkaitan dengan shalat.

Sementara itu, langkah-langkah pembelajaran pendidikan agama Islam di madrasah yang dilaksanakan dengan konsep pendidikan pragmatis dengan menggunakan teori William N Bender, yaitu: ${ }^{23}$

1. Persiapan Pembelajaran

a. Pembelajaran dimulai dengan guru mengucapkan salam dan berdoa bersama.

b. Memeriksa kehadiran, kerapian berpakaian, posisi tempat duduk disesuaikan dengan kegiatan pembelajaran.

c. Menyapa peserta didik.

d. Melaksanakan apersepsi dan pretes.

e. Menyampaikan tujuan pembelajaran.

f. Mempersiapkan alternatif metode pembelajaran, yaitu metode proyek.

2. Pelaksanaan Pembelajaran

a. Peserta didik menyimak dan mencermati tayangan atau gambar yang di tampilkan oleh guru tentang materi yang dipelajari.

b. Peserta didik bertanya/memberi komentar terhadap tayangan atau gambar tersebut.

c. Peserta didik diberikan penjelasan tentang maksud yang terkandung di dalam tayangan atau gambar tersebut.

d. Guru membagi peserta didik menjadi beberapa kelompok sesuai dengan jumlah peserta yang diperlukan untuk memperagakan.

e. Peserta didik menyimak teks bacaan tentang materi yang dipelajari di dalam kelompoknya masing-masing.

${ }^{23}$ William N Bender, Project Based Learning: Differentiating Instruction for the 21st Century, (California: Corwin, 2012),17-20 
f. Peserta didik bertanya tentang materi yang dipelajari di dalam kelompoknya masing-masing.

g. Peserta didik mendiskusikan dan merancang proyek materi yang dipelajari berdasarkan kelompoknya masing-masing.

h. Hasil proyek setiap kelompok dipraktikkan atau dipresentasikan di depan kelompok lainnya.

i. Kelompok lain mengkritisi hasil presentasi proyek setiap kelompok.

j. Guru melakukan penilaian praktik yang dilakukan oleh peserta didik.

k. Peserta didik diberikan penjelasan tambahan dan penguatan materi oleh guru/pembimbing.

Berdasarkan langkah-langkah pembelajaran di atas, maka dapat diidentifikasi praktik pragmatisme dalam proses pembelajaran pendidikan agama Islam, yaitu materi pelajaran dipelajari secara gradual mulai dari yang sederhana hingga ke materi yang lebih kompleks. Selain itu, penampilan oleh masing-masing kelompok di depan kelompok lain merupakan bentuk belajar secara bertahap oleh peserta didik atas dasar pengalaman sendiri (langsung) melalui metode proyek menuju ke metode belajar berdasarkan pengalaman orang lain.

\section{KESIMPULAN}

Ciri khas dari pendidikan pragmatis adalah praktek langsung (Learning by Doing). Sehingga pendidikan pragmatis berorientasi kepada kebebasan siswa dalam mencari pengalaman belajar masing-masing yang akan membentuk karakter siswa dalam bimbingan seorang guru. Konsekeunasi praktik pragmatis maka madrasah tidak hanya berfungsi sebagai tempat mengasah kecerdasan kognitif tetapi juga sebuah laboratorium pengalaman yang mana ide-ide atau gagasan dapat diuji coba. Tujuan Pendidikan pragmatis di madrasah adalah pengembangan pemikiran, kesadaran sosial dan peningkatan kerohanian siswa.

Praktik pembelajaran pragmatis hendaknya dimulai dari pengalaman hidup yang bersifat umum dan menuju yang lebih kompleks. Kurikulum Pendidikan pragmatis di madrasah hendaknya menyesuaikan dengan kemampuan inteletual siswa. Di level yang lebih tinggi siswa hendaknya mampu memetik intisari pelajaran, keterangan dan penjelasan yang komprehensip melalui berbagai sumber dan metode Pendidikan berbasis proyek dan metode belajar berdasarkan pengalaman orang lain yang di desain secara bebas, merdeka dan terbimbing. 


\section{DAFTAR PUSTAKA}

Abd. Al-Rahman Ibn Khaldun, Muqaddimah Ibn Khaldun, Tahqiq Ali Abd al-Wahid Wafi, Cairo: Dar al-Nandhah, 1982.

Ahmad Falah, Konsep Pendidikan Anak Menurut Ibnu Khaldun (Studi Atas Kitab Muqaddimah), Thufula, Vol. 2, No. Januari-Juni 2014.

George R. Knight, Filsafat Pendidikan, terj Mahmud Arif, Yogyakarta: Gama Media, 2007.

Hamam Burhanuddin, Dekontruksi Pemikiran Ibnu Khaldun Tentang Pendidikan, Edukasi, Volume 03, Nomor 01, Juni, 2015.

Ilun Muallifah, Progrevisme Jhon Dewew dan pendidikan partisipatif dalam pendidikan Islam, Jurnal Pendidikan Agama Islam, volume 1, No 1, 2013.

Iman, Muis Saad, Pendidikan Partisipatif: Menimbang Konsep Fitrah dan Progresivisme John Dewey, Yogyakarta, Safiria Insani Press, 2004.

John Dewey, Democracy and Education, Nerv York: Macmillan, 1964.

Joko Subagyo, Metode Penelitian dan Praktek, Jakarta: Rhineka Cipta, 1991.

lryoh Sadulloh, Pengantar Filsat'at Pendidihan, Bandung: Alfa Bera, 2007.

Muh. Barid Nizaruddin Wajdi, Pendidikan Ideal Menurut Ibnu Khaldun dalam Muqaddimah, Jurnal Lentera: Kajian Keagamaan, Keilmuan dan Teknologi Volume 1, Nomor 2, September 2015.

Muhammad Jawwad Ridla, Tiga Aliran Utama Teori Pendidikan Islam, perspektif Sosiologis-Filosofis, Yogyakarta: Tiara Wacana.

Musyarapah, The Role of Progressive Philosophy in the Curriculum Based on John Dewey's Theory, Al-hayat, Volume 01, Nomor 01, November 2017.

Setiawan, A., Pengembangan Sebuah Ruang Kelas Belajar Serta Aplikasi Learning By Doing di Sekolah High Schope Indonesia, Proceedings: 1st International Symposium on Conducive Learning Environment for Smart School (Cles), 2011.

Siti Rohmah, Relevansi Konsep Pendidikan Islam Ibnu Khaldun Dengan Pendidikan Modern, Forum Tarbiyah Vol. 10, No. 2, Desember 2012, hlm. 277

T. Saiful Akbar , Manusia Dan Pendidikan Menurut Pemikiran Ibn Khaldun Dan John Dewey, Jurnal Ilmiah Didaktika Vol. 15, No. 2, Februari 2015.

Wasitohadi, "Pragmatisme, Humanisme dan Implikasinya Bagi Dunia Pendidikan di Indonesia”, dalam Satya Widya, Vol. 28, No. 2, 2012.

William N Bender, Project Based Learning: Differentiating Instruction for the 21st Century, (California: Corwin, 2012) 
Wiranata, Firman, Mulyanto, Prastowo, Praktik Pembelajaran di Madrasah Perspektif Pragmatsime 